\title{
High expression of Talin-1 is associated with poor prognosis in patients with nasopharyngeal carcinoma
}

Ya-Fei Xu ${ }^{\dagger}$, Xian-Yue Ren ${ }^{\dagger}$, Ying-Qin Li, Qing-Mei He, Xin-Ran Tang, Ying Sun, Jian-Yong Shao, Wei-Hua Jia, Tie-Bang Kang, Mu-Sheng Zeng, Na Liu* and Jun Ma*

\begin{abstract}
Background: Talin-1 is a cytoskeletal protein that plays an important role in tumourgenesis, migration and metastasis in several malignant tumors. The aim of this study was to evaluate the expression and prognostic value of Talin-1 in nasopharyngeal carcinoma (NPC).

Methods: Talin-1 mRNA and protein expression were examined in NPC cell lines and clinical nasopharyngeal tissues by quantitative RT-PCR, agarose gel electrophoresis and western blotting. The expression of Talin-1 was analyzed by immunohistochemical staining in 233 paraffin-embedded NPC specimens with clinical follow-up data and cox regression analysis was used to identify independent prognostic factors. The functional role of Talin-1 in NPC cell lines was evaluated by small interfering RNA-mediated depletion of the protein followed by the wound healing and transwell invasion assays.

Results: The expression of Talin-1 was significantly upregulated in most NPC cell lines and clinical tissues at both the mRNA and protein levels. High expression of Talin-1 was significantly associated with distant metastasis $(P=0.001)$ and patient death $(P=0.001)$. In addition, high expression of Talin-1 was associated with significantly poorer overall survival (OS: HR, 2.15; 95\% Cl, 1.28-3.63; $P=0.003$ ) and poorer distant metastasis-free survival (DMFS: HR, 2.39; 95\% Cl, 1.38-4.15; $P=0.001)$. Cox regression analysis indicated that high expression of Talin-1 and TNM stage were independent prognostic indicators (both $P<0.05$ ). Stratified analysis demonstrated that high expression of Talin-1 was associated with significantly poorer survival in patients with advanced stage disease (stage IIIIIV, HR, 1.91; 95\% Cl, 1.09-3.35; $P=0.02$ for OS and HR, 2.22; $95 \% \mathrm{Cl}, 1.24-3.99 ; P=0.006$ for DMFS). Furthermore, the depletion of Talin-1 suppressed the migratory and invasive ability of NPC cells in vitro.
\end{abstract}

Conclusions: Our data demonstrate that high expression of Talin-1 is associated with significantly poorer OS and poorer DMFS in NPC and depletion of Talin-1 expression inhibited NPC cell migration and invasion. Talin-1 may serve as novel prognostic biomarker in NPC.

Keywords: Talin-1, Nasopharyngeal carcinoma, Prognosis, Biomarker

\footnotetext{
*Correspondence: liun1@sysucc.org.cn; majun2@mail.sysu.edu.cn

${ }^{\dagger}$ Equal contributors

State Key Laboratory of Oncology in South China; Collaborative Innovation

Center for Cancer Medicine, Sun Yat-sen University Cancer Center, 651

Dongfeng Road East, Guangzhou, People's Republic of China
} 


\section{Background}

Nasopharyngeal carcinoma (NPC) is rare in most populations throughout the world, but is relatively common in Southern China and Southeast Asia where the incidence is as high as 20 to 50 per 100,000 person-years [1-4]. There were an estimated 84,400 incident cases of NPC and 51,600 NPC-related deaths in 2008 according to data from the International Agency for Research on Cancer [5]. Due to anatomic constraints and its high radiosensitivity, early-stage NPC is typically treated using radiotherapy, whereas chemoradiotherapy is the standard treatment for advanced NPC [6].

Currently, the clinical TNM (tumor, node, metastasis) staging system for NPC is most frequently used to estimate prognosis. However, large variations are observed in the clinical outcomes of patients with the same stage of disease who undergo similar therapies, indicating that the TNM staging system alone is inadequate for accurately predicting prognosis $[7,8]$. With progress in molecular biology, the identification of molecular biomarkers may provide additional value to prognostic predictions. In recent years, several molecular biomarkers have been identified to be associated with prognosis in NPC, such as breast cancer metastasis suppressor 1 (BRMS1), metastasis-associated protein 1 (MTA1), Dicer 11, centromere protein-H (CENP-H) and cancerous inhibitor of protein phosphatase 2A (CIP2A) [9-13]; however, prognostic prediction in NPC remains extremely poor [14]. Therefore, the discovery of novel biomarkers that could be utilized as more effective prognostic predictors would be of significant clinical value and furthermore could help to enable individualized treatment of patients with NPC.

Talin-1, a large $270 \mathrm{kDa}$ cytoskeletal protein that contains 2541 amino acids, is mainly expressed in the kidney, liver, spleen, stomach, lung and vascular smooth muscle and plays an essential role in integrin activation [15]. Previous studies demonstrated that the expression of Talin-1 was highly associated with endometrioid carcinoma, oral squamous cell carcinoma (OSCC), prostate cancer and hepatocellular carcinoma [16-20]. In addition, Talin-1 can promote cancer cell adhesion, migration and invasion, and may represent a diagnostic marker of aggressive phenotypes and a potential therapeutic target for prostate cancer and OSCC $[17,18]$. To date, however, the expression levels and clinical significance of Talin-1 in NPC remain largely unknown.

In the present study, we examined both the mRNA and protein expression levels of Talin-1 in NPC cell lines and clinical tissue samples, and also analyzed the association between Talin-1 expression and the clinical characteristics of a cohort of patients with NPC from Guangdong Province, an area of China where the population have a high risk of NPC. Furthermore, we evaluated the prognostic value of Talin-1, in order to develop a more personalized therapy for NPC.

\section{Methods}

\section{Cell lines and cell culture}

Human NPC cell lines (CNE-1, CNE-2, SUNE-1, C666-1, HNE1 and HONE1) were cultured in RPMI-1640 (Invitrogen, Carlsbad, CA, USA) medium supplemented with 10\% fetal bovine serum. The immortalized nasopharyngeal epithelial cell line (NP69) was cultured in keratinocyte/ serum-free medium (Invitrogen) supplemented with bovine pituitary extract, as previously described [12]. All cell lines were incubated at $37^{\circ} \mathrm{C}$ in a $5 \% \mathrm{CO}_{2}$ incubator.

\section{Patients and tissue specimens}

Eight freshly-frozen NPC specimens and six normal nasopharyngeal epithelium samples were obtained from Sun Yat-sen University Cancer Center. In addition, a total of 233 pretreatment paraffin-embedded NPC specimens were collected from our hospital between January 2003 and February 2006; none of the 233 NPC patients had received radiotherapy or chemotherapy before biopsy. The clinical characteristics of all patients were recorded (Table 1). All patients were treated with conventional twodimensional radiotherapy, and patients with stage III-IV disease also received platinum-based concurrent chemotherapy $[21,22]$. The median follow-up time for the entire cohort was 63.2 months (range, 5.2-91.87). The following end points (time to the first defining event) were assessed: 5-year overall survival (OS) and distant metastasis-free survival (DMFS). This study was approved by the Institutional Ethical Review Board of Sun Yat-sen University Cancer Center, and written informed consent was obtained from each patient.

\section{RNA extraction, reverse transcription, quantitative RT-PCR} and agarose gel electrophoresis

Total RNA was extracted from the cell lines using TRIzol reagent (Life Technologies, Grand Island, NY, USA). The extracted RNA $(2 \mu \mathrm{g})$ was reverse transcribed using random primers (Promega, Madison, WI, USA) and M-MLV reverse transcriptase (Promega) for $60 \mathrm{~min}$ at $37^{\circ} \mathrm{C}$ and then $15 \mathrm{~min}$ at $70^{\circ} \mathrm{C}$, and the product was stored at $-20^{\circ} \mathrm{C}$ until use. Quantitative RT-PCR was performed on the PRISM 7900HT sequence detection system (Applied Biosystems, Carlsbad, CA, USA) in $15 \mu \mathrm{L}$ reactions containing $0.5 \mu \mathrm{L}$ of reverse transcription product, $7.5 \mu \mathrm{L}$ of Platinum SYBR Green qPCR SuperMix-UDG reagents (Invitrogen), $1.5 \mu \mathrm{L}$ of each PCR forward primer and reverse primer (final concentration, $2.5 \mu \mathrm{M}$ ), and $5.5 \mu \mathrm{L}$ of $\mathrm{ddH}_{2} \mathrm{O}$. The reactions were pre-incubated at $95^{\circ} \mathrm{C}$ for $10 \mathrm{~min}$, followed by 40 cycles of denaturation at $95^{\circ} \mathrm{C}$ for $30 \mathrm{~s}$ and annealing/extension at $60^{\circ} \mathrm{C}$ for $1 \mathrm{~min}$, then 
Table 1 Clinical characteristics of the patients with nasopharyngeal carcinoma stratified by low and high expression of Talin-1

\begin{tabular}{|c|c|c|c|c|}
\hline \multirow[t]{2}{*}{ Characteristic } & \multirow[t]{2}{*}{ No. of patients } & \multicolumn{2}{|c|}{ Expression of talin-1 } & \multirow[t]{2}{*}{$P$-value* } \\
\hline & & Low, n (\%) & High, n (\%) & \\
\hline \multicolumn{5}{|l|}{ Age } \\
\hline$\leq 45$ years & 114 & $87(76.3)$ & $27(23.7)$ & 0.09 \\
\hline$>45$ years & 119 & $79(66.4)$ & 40 (33.6) & \\
\hline \multicolumn{5}{|l|}{ Sex } \\
\hline Male & 169 & $124(73.4)$ & $45(26.6)$ & 0.24 \\
\hline Female & 64 & $42(65.6)$ & $22(34.4)$ & \\
\hline \multicolumn{5}{|l|}{ WHO type } \\
\hline$|+| \mid$ & 8 & $4(50.0)$ & $4(50.0)$ & 0.23 \\
\hline III & 225 & $162(72.0)$ & $63(28.0)$ & \\
\hline \multicolumn{5}{|l|}{ VCA-IgA } \\
\hline$<1: 80$ & 35 & $27(77.1)$ & $8(22.9)$ & 0.40 \\
\hline$\geq 1: 80$ & 198 & $139(70.2)$ & $59(29.8)$ & \\
\hline \multicolumn{5}{|l|}{$E A-\lg A$} \\
\hline$<1: 10$ & 57 & $42(73.7)$ & $15(26.3)$ & 0.64 \\
\hline$\geq 1: 10$ & 176 & $124(70.5)$ & $52(29.5)$ & \\
\hline \multicolumn{5}{|l|}{ T Stage } \\
\hline T1-T2 & 113 & $85(75.2)$ & $28(24.8)$ & 0.19 \\
\hline Т3-Т4 & 120 & $81(67.5)$ & $39(32.5)$ & \\
\hline \multicolumn{5}{|l|}{ N Stage } \\
\hline NO-N1 & 143 & $103(72.0)$ & $40(28.0)$ & 0.74 \\
\hline N2-N3 & 90 & $63(70.0)$ & $27(30.0)$ & \\
\hline \multicolumn{5}{|l|}{ TNM stage } \\
\hline$|-| \mid$ & 72 & $56(77.8)$ & $16(22.2)$ & 0.14 \\
\hline III-IV & 161 & $110(68.3)$ & $51(31.7)$ & \\
\hline \multicolumn{5}{|c|}{ Locoregional failure } \\
\hline Yes & 39 & $23(59.0)$ & $16(41.0)$ & 0.06 \\
\hline No & 194 & $143(73.7)$ & $51(26.3)$ & \\
\hline \multicolumn{5}{|c|}{ Distant metastasis } \\
\hline Yes & 51 & $27(52.9)$ & $24(47.1)$ & 0.001 \\
\hline No & 182 & $139(76.4)$ & $43(23.6)$ & \\
\hline \multicolumn{5}{|l|}{ Death } \\
\hline Yes & 57 & $31(54.4)$ & $26(45.6)$ & 0.001 \\
\hline No & 176 & 135 (76.7) & $41(23.3)$ & \\
\hline
\end{tabular}

Abbreviations: WHO: World Health Organization; VCA-IgA: viral capsid antigen immunoglobulin A; EA-lgA: early antigen immunoglobulin A. P-values* were calculated using the chi-square test or Fisher's exact test.

ramped from $60^{\circ} \mathrm{C}$ to $95^{\circ} \mathrm{C}$ to obtain a melting curve. The following PCR primers were used: Talin-1 forward, 5 ' -CTG GAGGCAACCACAGAAC-3' and Talin-1 reverse, 5' -GT GGCTCTGGGGAACAGA-3'; glyceraldehyde-3-phosphate dehydrogenase (GAPDH) forward, 5 ' -CTCCTCCTGTTC GACAGTCAGC-3' and GAPDH reverse, 5' -CCCAATAC GACCAAATCCGTT $-3^{\prime}$. All of the assays were performed in triplicate, and reactions containing either no template or no reverse transcriptase were used as negative controls. GAPDH was used as the normalization control. Agarose gel electrophoresis was performed to examine the mRNA expression level of Talin-1. PCR amplications were performed using the GoTaq Green Master Mix kit (Promega, USA) and PCR cycling conditions were as follows: $95^{\circ} \mathrm{C}$ for $2 \mathrm{~min}$, followed by 27 cycles of $95^{\circ} \mathrm{C}$ for $30 \mathrm{~s}, 53^{\circ} \mathrm{C}$ for $30 \mathrm{~s}$ and $72^{\circ} \mathrm{C}$ for $8 \mathrm{~s}$, then extension at $72^{\circ} \mathrm{C}$ for $5 \mathrm{~min}$ (Biorad, S1000 Thermal Cycler, USA). PCR products were checked by $1.5 \%$ agarose gel electrophoresis.

\section{Western blotting}

Total proteins were extracted using sample buffer (62.5 mmol/L Tris-HCl, pH 6.8, 2\% SDS, 10\% glycerol, and $5 \% 2-\beta$-mercaptoethanol), and the protein concentration was quantified using the Pierce ${ }^{\circ}$ BCA Protein Assay Kit (Thermo Scientific, Rockford, IL, USA). Total proteins were separated on 6\% SDS-PAGE gels and transferred onto polyvinylidene fluoride membranes (Millipore, Billerica, MA, USA). The membranes were blocked with 5\% skimmed-milk powder in Tris buffered saline with tween-20 (TBS-T), incubated with mouse monoclonal anti-Talin-1 (clone 1A11) antibody (1:200; Abnova, Taipei, Taiwan), then incubated with anti-mouse IgG secondary antibody (1:5,000; Sigma, St. Louis, MO, USA). The bands were detected by enhanced chemiluminescence; $\alpha$-tubulin antibody (1:5,000; Epitomics) was used as a loading control.

\section{Immunohistochemical staining}

The expression of Talin- 1 in the sections from the 233 paraffin-embedded NPC specimens was examined by immunohistochemical staining, as described previously [23]. Briefly, the tissue blocks were cut into $5 \mu \mathrm{m}$-thick sections, followed by deparaffinization and rehydration. The sections were microwaved for antigen retrieval in EDTA buffer, and 3\% hydrogen peroxide was used to quench endogenous peroxidase activity. Non-specific binding was blocked using $1 \%$ bovine serum albumin. The sections were then incubated overnight at $4^{\circ} \mathrm{C}$ with mouse monoclonal anti-Talin-1 (clone 1A11) antibody (1:100; Abnova); normal goat serum was used as a negative control. After rinsing, the sections were incubated with biotinylated secondary antibody bound to a streptavidinhorseradish peroxidase complex. The bound antibody was visualized by adding 3,3-diaminobenzidine, and then the sections were counterstained with hematoxylin, dehydrated and mounted.

The sections were scored independently by two pathologists, and any disagreements were resolved by consensus. Both the proportion of positively-stained tumor cells and the intensity of staining were assessed [23,24]. The proportion of positive tumor cells was scored as 
follows: $1(<10 \%), 2$ (10-35\%), 3 (35-70\%), and 4 (>70\%). The intensity of staining was graded on a scale from 0 to 3 as follows: 0 (no staining), 1 (weak staining, light yellow), 2 (moderate staining, yellow brown), and 3 (strong staining, brown). The staining index was calculated as the product of the staining intensity score and the proportion of positive tumor cells; using this method, staining index scores of $0,1,2,3,4,6,8,9$ or 12 were possible. The optimal cutoff value for high and low expression was selected based on a receiver operating characteristic (ROC) curve analysis, as previously described $[9,25-27]$. The best cutoff score of Talin-1 was 5. Therefore, a staining index score of $<5$ was used to define NPC with low Talin-1 expression and a staining index score of $>5$ was designated as high Talin- 1 expression.

\section{Oligonucleotide transfection}

CNE-2 or SUNE-1 cells were seeded into six-well plates $24 \mathrm{~h}$ prior to transfection. The Talin-1-silencing oligonucleotides (siTalin-1) or the respective controls (siCont) (GenePharma, Shanghai, China),) were transfected into the cells at a final concentration of $100 \mathrm{nmol} / \mathrm{L}$ using Lipofectamine $^{\mathrm{Tw}} 2000$ (Invitrogen). The cells were harvested $48 \mathrm{~h}$ after transfection for the specified assays.

\section{Wound healing assay}

For the wound healing assay, transfected CNE-2 or SUNE-1 cells were seeded into 6-well plates. After serum starvation in serum-free media for $24 \mathrm{~h}$, an artificial wound was created on the confluent cell monolayer using a standard $200 \mu \mathrm{l}$ plastic pipette tip. Cells migrated into the scratch area as single cells from the confluent sides; the width of the scratch gap was viewed under an inverted microscope and photographed at $0 \mathrm{~h}$ and $24 \mathrm{~h}$. Three replicate wells from a six-well plate were used for this experiment.

\section{Transwell invasion assays}

Invasion assays were performed in Transwell chambers (Corning, Steuben County, New York, USA) coated with Matrigel (BD Biosciences) on the upper surface of membrane with $8 \mu \mathrm{m}$-pore size. In brief, transfected CNE-2 or SUNE-1 cells were harvested, suspended in serumfree medium and $1 \times 10^{5}$ transfected cells were plated into the upper chamber for the invasion assays, and media supplemented with $10 \% \mathrm{FBS}$ was placed into the lower chamber. After incubation for $24 \mathrm{~h}$, the cells that had invaded through the membrane to the lower surface were fixed, stained and counted under an inverted microscope. Five random fields of view were analyzed for each chamber; three independent experiments were conducted for each assay.

\section{Statistical analysis}

The Chi-square test or Fisher's exact test were used to analyze the relationships between Talin-1 protein expression and clinical characteristics. Talin-1 mRNA expression levels in normal nasopharyngeal epithelial tissues and NPC tissues were analyzed using the Student's $t$-test. For functional analyses, data were presented as mean \pm standard deviation and Student's $t$-tests were used to determine the significance of the differences between two groups. The Kaplan-Meier method was used to estimate OS and DMFS, and the differences were compared using the logrank test. A Cox proportional hazards regression analysis with backward stepwise selection was used to identify independent predictive factors for OS and DMFS and calculate hazard ratio (HR) values. The Talin-1 expression level, age, sex, clinical stage, WHO type, VCA-IgA and EA-IgA were included as covariates. All statistical analyses were performed using SPSS 16.0 software (SPSS, Chicago, IL, USA); two-tailed $P$-values $<0.05$ were considered significant.

\section{Results}

Talin-1 is upregulated in NPC cells and tissues

The mRNA and protein expression levels of Talin-1 in the normal nasopharyngeal epithelial cell line NP69 and NPC cell lines were assessed by quantitative RT-PCR, agarose gel electrophoresis and Western blot analysis. Compared to NP69 cells, Talin-1 was significantly upregulated in all NPC cell lines tested at both the mRNA and protein levels, except for HNE1 cells (Figure 1A, C, E). Furthermore, we assessed the mRNA and protein levels of Talin-1 in eight freshly-frozen NPC tissues and six normal nasopharyngeal epithelial tissues, and observed that both Talin-1 mRNA and protein were expressed at considerably higher levels in the NPC tissues (Figure 1B, D, F). These results suggest that overexpression of Talin-1 may be involved in the progression of NPC.

\section{Associations between Talin-1 expression and the clinico- pathological features of NPC}

To identify the associations between Talin-1 protein expression and the clinical features of patients with NPC, we analyzed Talin-1 protein expression in a set of 233 paraffin-embedded NPC tissue samples using immunohistochemistry. Representative images of Talin-1 immunohistochemical staining in NPC tissues are shown in Figure 2A-D. Positive staining for Talin-1 was mainly observed in the cytoplasm of the NPC cells. Talin-1 expression was found in 182 out of 233 (78.1\%) NPCs. Using a staining index of 5 as the cutoff point in the 233 patients with NPC examined, we classified 166 (71.2\%) patients with low expression of Talin-1 and 67 (28.8\%) patients with high expression of Talin-1. As shown in Table 1, high Talin-1 expression was significantly associated 


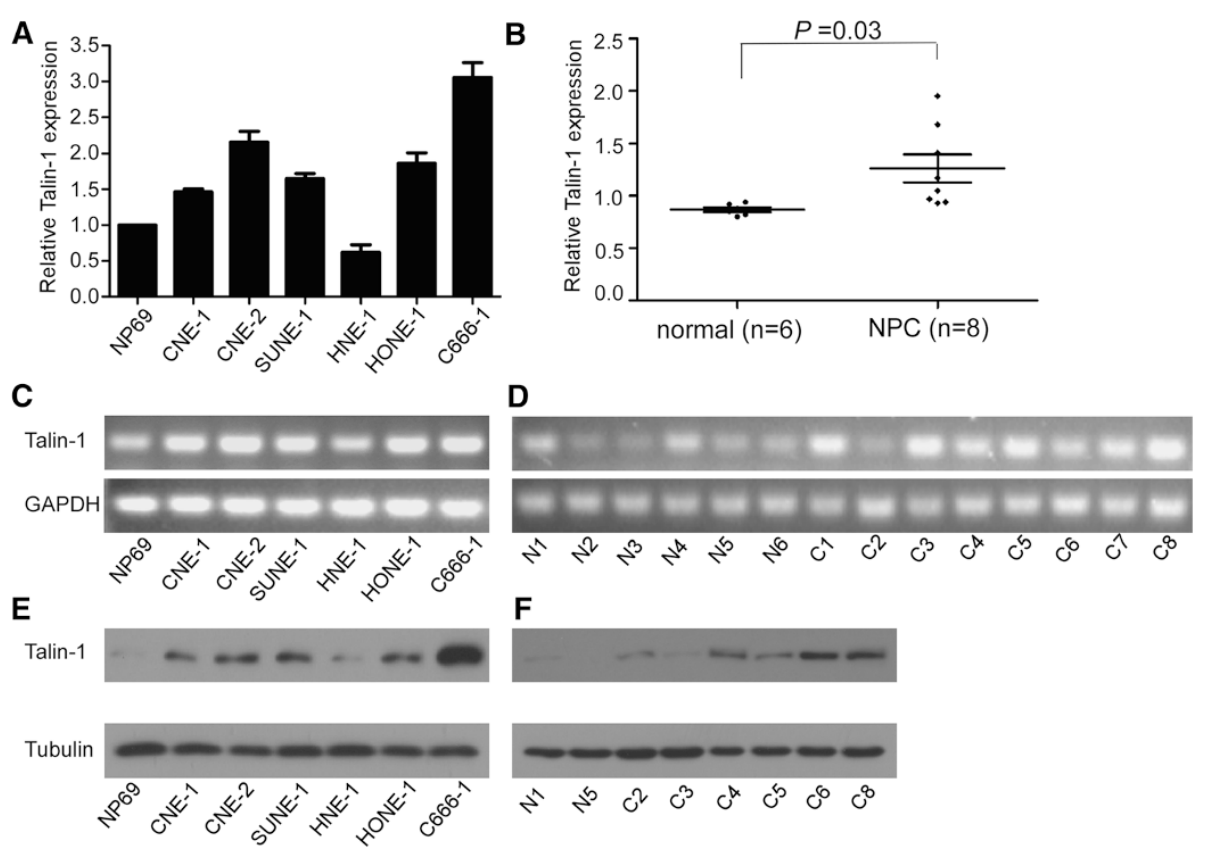

Figure 1 Talin-1 mRNA and protein expression in NPC cell lines and tissues. (A and B) Quantitative RT-PCR analysis of Talin-1 expression levels in the NP69 and NPC cell lines and in NPC $(n=8)$ and normal nasopharyngeal epithelial tissues $(n=6)$. (C and D) Agarose gel electrophoresis of Talin-1 expression in the NP69 and NPC cell lines and in NPC $(n=8)$ and normal nasopharyngeal epithelial tissues $(n=6)$. (E and F) Western blotting analysis of Talin-1 protein expression in the NP69 and NPC cell lines and in NPC and normal nasopharyngeal epithelial tissues. Data is presented as mean \pm SD values; the $P$-value was calculated using the Student's $t$-test.

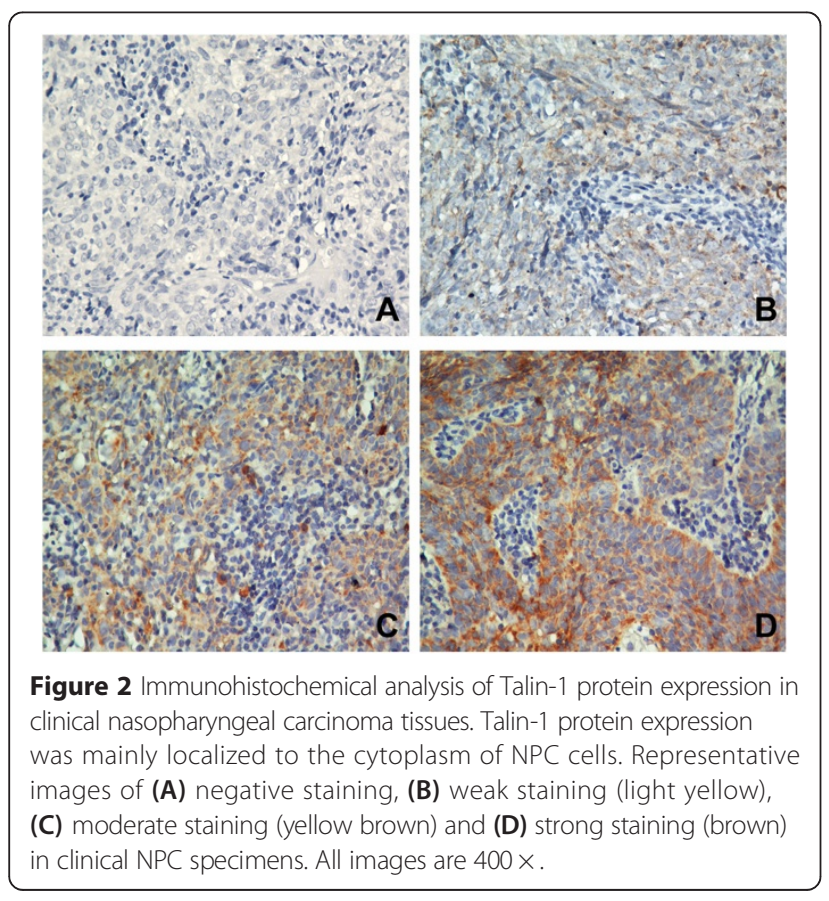

with distant metastasis $(P=0.001)$ and patient death $(P=0.001)$. However, there were no significant associations between Talin-1 expression and other clinical features, such as age, sex, WHO type, VCA-IgA, EA-IgA, clinical stage (T stage, $\mathrm{N}$ stage or TNM stage) or locoregional failure $(P>0.05)$.

High expression of Talin-1 is associated with a poor prognosis in NPC

The relationship between Talin-1 expression and survival in NPC was assessed using Kaplan-Meier analysis and the log-rank test. As shown in Figure 3, high Talin-1 expression was associated with significantly poorer OS (HR, 2.15; 95\% CI, 1.28-3.63; $P=0.003)$ and poorer DMFS (HR, 2.39; 95\% CI, 1.38-4.15; $P=0.001$; Figure 3A-B). The cumulative 5-year survival rate for the low Talin-1 expression group was $78.8 \%$ (95\% CI, $75.0-82.5$ ) compared to only $68.4 \%$ (95\% CI, $61.0-75.8$ ) for the high Talin-1 expression group.

Furthermore, stratified analysis indicated that in the subgroup with early-stage NPC (stage I-II, $n=72$ ), the differences in OS and DMFS between patients with high or low Talin-1 expression were not significant $(P=0.25$ and $P=0.47$, respectively; Figure $4 \mathrm{~A})$. However, in the advanced disease subgroup (stage III-IV, $n=161$ ), patients with high Talin-1 expression had significantly poorer OS (HR, 1.91; 95\% CI, 1.09-3.35; $P=0.02$ ) and 

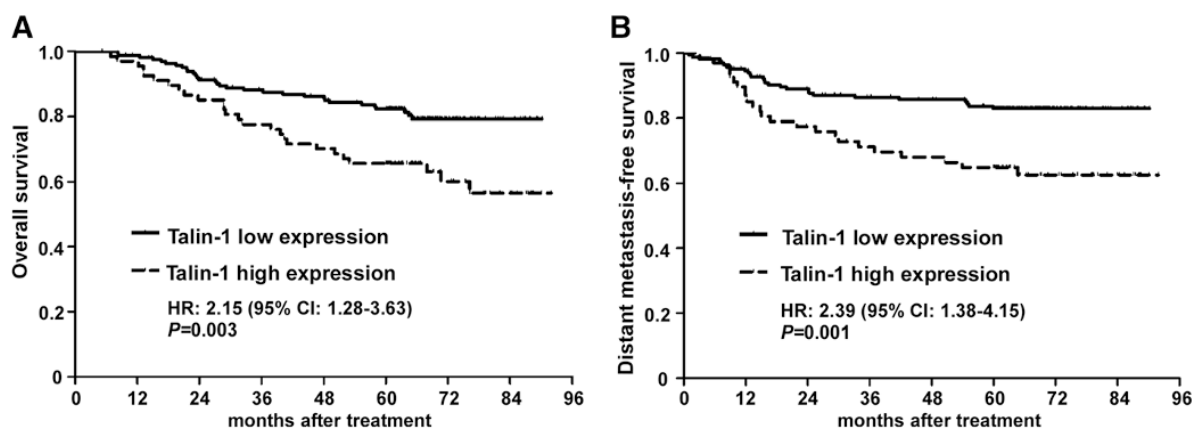

Figure 3 Overall and distant metastasis-free survival for patients stratified by low and high expression of Talin-1. Kaplan-Meier (A) overall survival and (B) distant metastasis-free survival curves for patients with nasopharyngeal carcinoma $(n=233)$ stratified by low and high expression of Talin-1. HR, hazard ratio, and $\mathrm{Cl}$, confidence interval; $\mathrm{HR}$ values were calculated using unadjusted Cox regression analyses; $P$-values were calculated using the log-rank test.

poorer DMFS (HR, 2.22; 95\% CI, 1.24-3.99; $P=0.006)$ than those with low Talin-1 expression (Figure 4B). These results suggest that high expression of Talin-1 is associated with a poorer prognosis in NPC, especially in patients with advanced disease (stage III-IV).

\section{High expression of Talin-1 is an independent prognostic factor in NPC}

Univariate and multivariate Cox regression analyses were carried out to investigate the effect of different clinical variables, including Talin-1 expression, TNM stage, age, sex, WHO type, VCA-IgA and EA-IgA, on OS and DMFS. As shown in Table 2, univariate analyses indicated that high Talin-1 expression was associated with significantly poorer $O S$ and poorer DMFS ( $P=0.004$ and 0.002 , respectively) compared to low Talin-1 expression. In addition, advanced stage disease (stage III-IV) was associated with significantly poorer OS and poorer DMFS $(P=0.003$ and 0.002 , respectively) compared to early stage disease (stage I-II). However, age, sex, WHO type, VCA-IgA and EA-IgA had no significant impact on OS or DMFS (all $P>0.05$ ). Furthermore, multivariate analyses confirmed that high expression of Talin-1 and TNM stage were independent prognostic indicators associated with OS and DMFS in NPC (both $P<0.05)$.
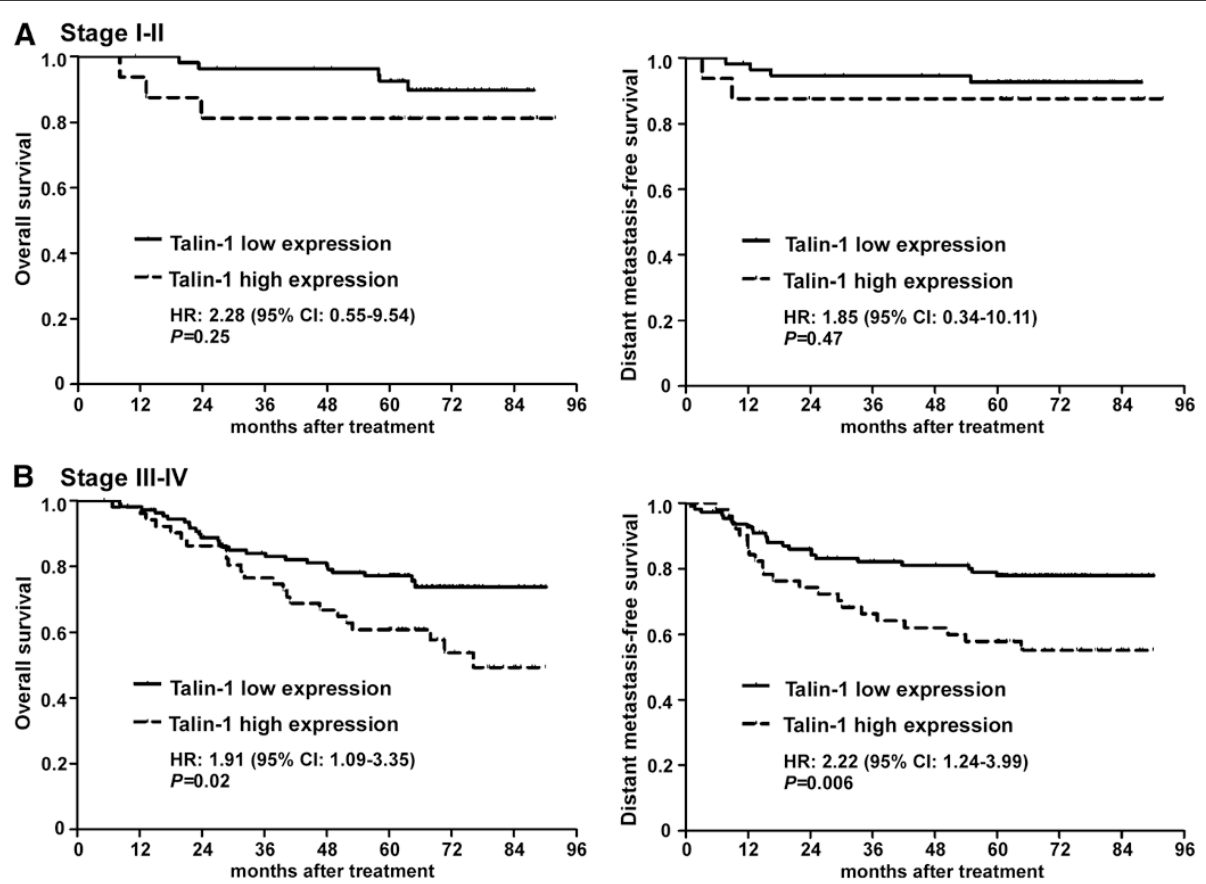

Figure 4 Upregulation of Talin-1 is associated with poor survival in advanced nasopharyngeal carcinoma. Overall and distant metastasis-free survival curves for patients with (A) Stage I-II $(n=72)$ and (B) Stage III-IV $(n=161)$ nasopharyngeal carcinoma. Hazard ratio (HR) and confidence interval (Cl) values were calculated using unadjusted Cox regression analyses; $P$-values were calculated using the log-rank test. 
Table 2 Univariate and multivariate cox regression analyses of prognostic factors in nasopharyngeal carcinoma

\begin{tabular}{|c|c|c|c|c|c|c|}
\hline \multirow[b]{2}{*}{ Variable } & \multicolumn{3}{|c|}{ Univariate analysis } & \multicolumn{3}{|c|}{ Multivariate analysis } \\
\hline & HR & $95 \% \mathrm{Cl}$ & $P$-value ${ }^{*}$ & $\mathrm{HR}$ & $95 \% \mathrm{Cl}$ & $P$-value* \\
\hline \multicolumn{7}{|l|}{ Overall survival } \\
\hline Talin-1 expression (high vs. low) & 2.15 & $1.28-3.63$ & 0.004 & 1.87 & $1.10-3.16$ & 0.02 \\
\hline TNM stage (III-IV vs. I-II) & 3.06 & $1.45-6.47$ & 0.003 & 2.97 & $1.40-6.29$ & 0.005 \\
\hline Age ( $\geq 45$ years vs. $<45$ years) & 1.63 & $0.96-2.78$ & 0.07 & & & \\
\hline Sex (male vs. female) & 1.57 & $0.83-2.96$ & 0.17 & & & \\
\hline WHO Type (III vs. I-II) & 0.63 & $0.20-2.03$ & 0.44 & & & \\
\hline VCA-lgA ( $\geq 1: 80$ vs. $<1: 80)$ & 1.50 & $0.64-3.49$ & 0.35 & & & \\
\hline EA-lgA ( $\geq 1: 10$ vs. $<1: 10)$ & 1.04 & $0.56-1.93$ & 0.90 & & & \\
\hline \multicolumn{7}{|l|}{ Distant metastasis-free survival } \\
\hline Talin-1 expression (high vs. low) & 2.39 & $1.38-4.15$ & 0.002 & 2.18 & $1.25-3.78$ & 0.006 \\
\hline TNM stage (III-IV vs. I-II) & 3.78 & $1.61-8.86$ & 0.002 & 3.48 & $1.48-8.17$ & 0.004 \\
\hline Age ( $\geq 45$ years vs. $<45$ years) & 1.58 & $0.90-2.78$ & 0.11 & & & \\
\hline Sex (male vs. female) & 1.51 & $0.77-2.94$ & 0.23 & & & \\
\hline WHO Type (III vs. I-II) & 0.54 & $0.17-1.73$ & 0.30 & & & \\
\hline VCA-IgA ( $\geq 1: 80$ vs. $<1: 80)$ & 1.10 & $0.50-2.45$ & 0.81 & & & \\
\hline EA-lgA ( $\geq 1: 10$ vs. $<1: 10)$ & 1.30 & $0.65-2.60$ & 0.45 & & & \\
\hline
\end{tabular}

Abbreviations: WHO: World Health Organization; VCA-IgA: viral capsid antigen immunoglobulin A; EA-lgA: early antigen immunoglobulin A. P-values* were calculated using univariate and multivariate cox regression analyses.

\section{Talin-1 depletion has significant effect on the NPC cell} migration and invasion in vitro

To investigate the effects of aberrant expression of Talin-1 on the migratory and invasive ability of NPC cells, CNE-2 and SUNE-1 cells were transfected with siTalin-1 or siCont. Figures $5 \mathrm{~A}$ showed that Talin-1 protein levels were significantly reduced by transfection of siTalin-1. The wound healing assay demonstrated that the migratory ability of CNE-2 and SUNE-1 cells transfected with siTalin-1 was significantly lower than those of cells transfected with siCont (Figure 5B). In addition, the Transwell invasion assay showed that the invasive ability of NPC cells transfected with siTalin-1 was significantly lower than those of cells transfected with siCont (Figure $5 C ; " P<0.01$ ). These results indicate that Talin-1 depletion significantly reduces the migratory and invasive ability of NPC cells in vitro.

\section{Discussion}

The clinical prognosis of patients with NPC has improved significantly with recent advances in diagnostic technologies and therapeutic interventions. However, patients with the same clinical stage of NPC still have varying clinical outcomes when receiving identical therapeutic interventions. Therefore, it is particularly important to identify novel biomarkers that could more effectively predict prognosis and further help to achieve individualized treatment of patients with NPC. The present study demonstrates that Talin-1 is upregulated in NPC at both the mRNA and protein levels, and that high expression of Talin-1 is associated with a significantly poorer prognosis in patients with NPC. In addition, Talin-1 was identified as an independent prognostic indicator in multivariate analysis, indicating that Talin-1 may serve as a novel prognostic biomarker to guide clinical practice and research on NPC.

Talin-1 is a cytoskeletal protein that acts as a key adaptor protein to regulate integrin conformation and cell migration, and has been shown to play an important role in promoting tumor cell adhesion, migration and invasion in different types of cancer. Previous studies showed that high expression of Talin-1 was associated with a poor clinical prognosis in OSCC $[17,28]$. In addition, Sakamoto et al. reported that Talin-1 was significantly upregulated in primary tumors and metastatic prostate cancer compared with the normal prostate gland [18]. Furthermore, higher expression of Talin-1 was observed in triple-negative breast cancer cell lines, and low Talin-1 expression was a prognostic marker for better outcome after cytotoxic chemotherapy [29]. Together, these studies indicate that Talin-1 may serve as a potential diagnostic and prognostic marker of aggressive phenotypes and may represent a potential therapeutic target for various types of cancer.

In this study, the Talin-1 expression was found in 182 out of 233 (78.1\%) NPCs and the percent of Talin-1 overexpression was $28.8 \%$. Lai MT et al. revealed that the Talin-1 expression was found in 101 out of 163 


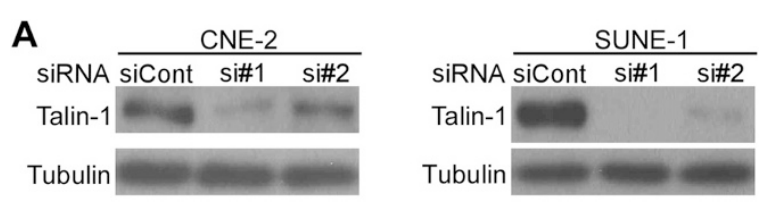

B
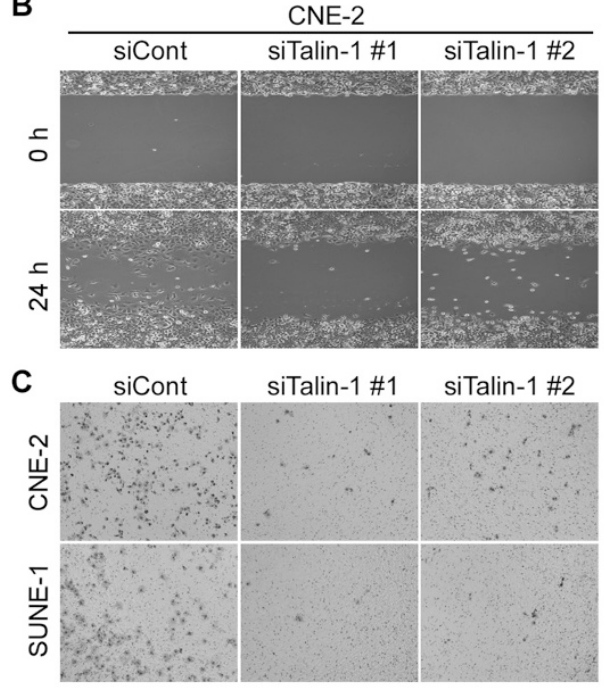
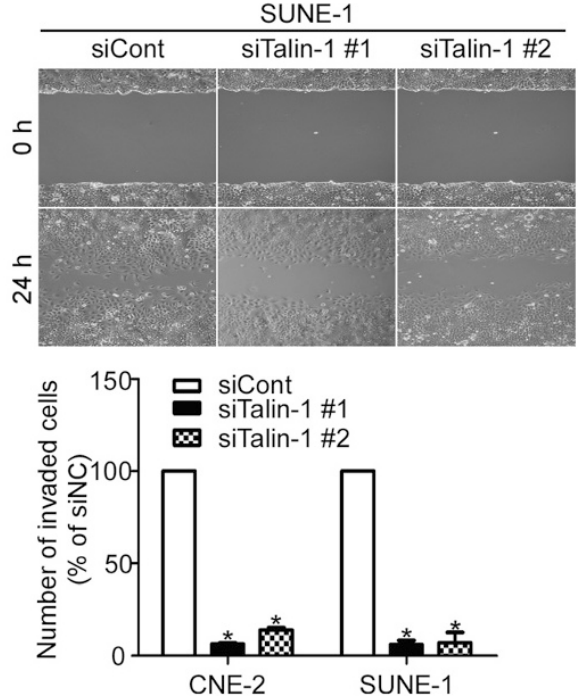

Figure 5 Talin-1 depletion had significant effect on the NPC cell migration and invasion in vitro. (A) Talin-1 protein expression by western blotting after transfection with siTalin-1 or siCont. (B) Representative images of the wound healing assay of CNE-2 and SUNE-1 cells transfected with siTalin-1 or siCont. (C) Representative images (left) and quantification (right) of the Transwell invasion assay of CNE-2 and SUNE-1 cells transfected with siTalin-1 or siCont. Values are mean $\pm \mathrm{SD} ;{ }^{*} P<0.01$.

(62\%) oral cavity cancer and the percent of Talin-1 overexpression was $19.6 \%$ [17]. The above results showed that the expression of Talin-1 were higher in NPC than that in oral cavity cancer. However, Talin-1 expression in hepatocellular carcinoma (HCC) was controversial. For example, Kanamori et al. found that Talin-1 was upregulated in HCC (60.4\%) [20]. On the other hand, Zhang et al. proved that Talin-1 was down-regulated in HCC liver tissues [19]. Therefore, we think that the expression of Talin-1 has tissue-specificity and further studies are needed to explore the role of Talin-1 in different cancers. In addition, we observed that high Talin1 expression was significantly associated with distant metastasis and patient death, but not with locoregional failure. These results suggest that overexpression of Talin-1 may be involved in the progression of NPC.

It is well-recognized that local control of NPC improved significantly with the advent of intensity-modulated radiotherapy, and that the majority of treatment failures and deaths in patients with NPC are currently attributable to distant metastasis [30]. Therefore, it is vital to detect metastasis-associated biomarkers that can effectively distinguish patients with NPC who are at a high risk of metastasis at the time of diagnosis. Integrin signaling plays a crucial role in cell invasion and migration, and a variety of extracellular matrix (ECM)-remodeling factors that may contribute to these processes have been identified [31-33]. As a focal adhesion complex protein that regulates integrin interactions with the ECM, Talin-1 has been identified as a novel regulator of the invasive and metastatic potential of tumor cells, as overexpression of Talin-1 significantly enhanced the migration and invasion of prostate cancer and OSCC cells in vitro, and was associated with advanced tumour stage and poorer clinical outcome $[17,18]$. In the present study, the wound healing assay and the transwell invasion assay showed that Talin-1 depletion could significantly reduce the migratory and invasive ability of NPC cells in vitro and survival analysis demonstrated that high expression of Talin-1 was associated with significantly poorer OS and DMFS in patients with NPC. Further stratified analysis revealed that high expression of Talin-1 was associated with significantly poorer survival in patients with stage III-IV disease. More importantly, multivariate analysis showed that high expression of Talin-1 was an independent prognostic factor in NPC. These results suggests that Talin-1 may be a useful prognostic biomarker for NPC. However, further studies are needed to confirm these findings in other cohorts of patients with NPC.

The mechanism of action of Talin- 1 during the development and progression of cancer is poorly characterized and may be complex. Talin-1 may trigger a conformational change in the extracellular domains of $\beta$ - 
integrin, which may increase the affinity of $\beta$-integrin for ECM proteins by linking the cytoplasmic domains of integrin $\beta$ subunits to actin filaments [34,35]. Previous studies had indicated that the activation of the FAK/AKT pathway was associated with increased proliferation, migration and invasion in a variety of tumors [36-39]. Recently, Sakamoto and colleagues found that overexpression of Talin-1 enhanced prostate cancer cell adhesion, migration and invasion by stimulating FAK, Src and GSK3 $\beta$ independently of integrin signaling and also conferred resistance to anoikis [18]. Other researchers reported that inhibition of the binding of Talin-1 to integrin could prevent integrin activation and downregulate downstream oncogenic signaling in vitro $[33,40]$.

To date, the mechanisms leading to the high expression of Talin-1 in human cancers are not very clear. Tang et al. found that TLN1 was overexpressed and associated with aggressiveness and metastasis in ovarian serous carcinoma and microRNA-9 could inhibit Talin-1 expression by targeting its 3'untranslated region and further led to the inhibition of the FAK/AKT pathway [41]. The current study indicates that Talin-1 plays an important role in the development and progression of NPC. Further investigation of the function and mechanism of action of Talin-1 may provide new opportunities for therapeutic targeting of NPC and we will further explore the precise mechanisms by which Talin-1 mediates progression and metastasis in NPC in a future study.

\section{Conclusions}

Talin-1 is upregulated at both the mRNA and protein levels in NPC. High expression of Talin-1 was significantly associated with poorer OS and DMFS in NPC, especially in patients with advanced stage disease (stage III-IV). Talin-1 may have potential as a novel prognostic biomarker and potential therapeutic target in NPC.

\section{Abbreviations \\ NPC: Nasopharyngeal carcinoma; IHC: Immunohistochemistry; WHO: World Health Organization; VCA-lgA: Viral capsid antigen immunoglobulin A; EA-IgA: Early antigen immunoglobulin A. OS, overall survival; DMFS: Distant metastasis-free survival; HR: Hazard ratio; Cl: Confidence interval; \\ OSCC: Oral squamous cell carcinoma; ECM: Extracellular matrix.}

\section{Competing interests}

The authors declare that they have no competing interests.

\section{Authors' contributions}

$J M, N L$, YFX were responsible for study design. YFX and XYR performed the experiments of $\mathrm{HC}$, quantitative RT-PCR, cellular studies, analyzed the results and drafted the manuscript. NL drafted the manuscript and participated in the data interpretation. YQL, QMH, and XRT carried out the western blot assays. JYS, WHJ, TBK, MSZ, and YS participated in the data collection and analysis. All authors have read and approved the final manuscript.

\section{Authors' information}

Requests for reprints should be addressed to the following authors: Jun Ma, State Key Laboratory of Oncology in South China, Sun Yat-sen University Cancer Center, 651 Dongfeng Road East, Guangzhou 510060,
People's Republic of China; Telephone: +86-20-87343469; Fax: +86-20-87343295; E-mail: majun2@mail.sysu.edu.cn

Na Liu, State Key Laboratory of Oncology in South China, Sun Yat-sen University Cancer Center, 651 Dongfeng Road East, Guangzhou 510060, People's Republic of China; Telephone: +86-20-87342370; Fax: +86-20-87343295; E-mail: liun1@sysucc.org.cn

\section{Acknowledgements}

This work was supported by grants from the Science and Technology Project of Guangzhou City, China (No.14570006), the Planned Science and Technology Project of Guangdong Province (No. 2013B020400004), the Health \& Medical Collaborative Innovation Project of Guangzhou City, China (201400000001), the National Science \& Technology Pillar Program during the Twelfth Five-year Plan Period (2014BAl09B10), and the Key Laboratory Construction Project of Guangzhou City (No.121800085).

Received: 4 July 2014 Accepted: 22 April 2015

Published online: 30 April 2015

\section{References}

1. Feng BJ, Huang W, Shugart YY, Lee MK, Zhang F, Xia JC, et al. Genome-wide scan for familial nasopharyngeal carcinoma reveals evidence of linkage to chromosome 4. Nat Genet. 2002;31(4):395-9.

2. Ou SH, Zell JA, Ziogas A, Anton-Culver H. Epidemiology of nasopharyngeal carcinoma in the United States: improved survival of Chinese patients within the keratinizing squamous cell carcinoma histology. Ann Oncol. 2007;18(1):29-35.

3. Ng WT, Choi CW, Lee MC, Chan SH, Yau TK, Lee AW. Familial nasopharyngeal carcinoma in Hong Kong: epidemiology and implication in screening. Fam Cancer. 2009;8(2):103-8.

4. Busson P, Ooka T, Corbex M. Nasopharyngeal carcinomas and Epstein-Barr virus: from epidemiology and detection to therapy. Med Sci (Paris). 2004;20(4):453-7.

5. Jemal A, Bray F, Center MM, Ferlay J, Ward E, Forman D. Global cancer statistics. CA Cancer J Clin. 2011;61(2):69-90.

6. Ma BB, Hui EP, Chan AT. Systemic approach to improving treatment outcome in nasopharyngeal carcinoma: current and future directions. Cancer Sci. 2008;99(7):1311-8.

7. Tatsumi-Tamori A, Yoshizaki T, Miwa T, Furukawa M. Clinical evaluation of staging system for nasopharyngeal carcinoma: comparison of fourth and fifth editions of UICC TNM classification. Ann Otol Rhinol Laryngol. 2000;109(12 Pt 1):1125-9.

8. Patel SG, Shah JP. TNM staging of cancers of the head and neck: striving for uniformity among diversity. CA Cancer J Clin. 2005;55(4):242-58. quiz 261-242, 264.

9. Cui RX, Liu N, He QM, Li WF, Huang BJ, Sun Y, et al. Low BRMS1 expression promotes nasopharyngeal carcinoma metastasis in vitro and in vivo and is associated with poor patient survival. BMC Cancer. 2012;12:376.

10. Li WF, Liu N, Cui RX, He QM, Chen M, Jiang N, et al. Nuclear overexpression of metastasis-associated protein 1 correlates significantly with poor survival in nasopharyngeal carcinoma. J Transl Med. 2012;10:78.

11. Liu N, Cui RX, He QM, Huang BJ, Sun Y, Xie D, et al. Reduced expression of Dicer11 is associated with poor prognosis in patients with nasopharyngeal carcinoma. Med Oncol. 2013;30(1):360.

12. Liao WT, Song LB, Zhang HZ, Zhang X, Zhang L, Liu WL, et al. Centromere protein $\mathrm{H}$ is a novel prognostic marker for nasopharyngeal carcinoma progression and overall patient survival. Clin Cancer Res. 2007;13(2 Pt 1):508-14.

13. Liu N, He QM, Chen JW, Li YQ, Xu YF, Ren XY, et al. Overexpression of CIP2A is an independent prognostic indicator in nasopharyngeal carcinoma and its depletion suppresses cell proliferation and tumor growth. Mol Cancer. 2014;13(1):111.

14. Cho WC. Nasopharyngeal carcinoma: molecular biomarker discovery and progress. Mol Cancer. 2007;6:1.

15. Giancotti FG, Ruoslahti E. Integrin signaling. Science. 1999;285(5430):1028-32.

16. Slater M, Cooper M, Murphy CR. The cytoskeletal proteins alpha-actinin, Ezrin, and talin are De-expressed in endometriosis and endometrioid carcinoma compared with normal uterine epithelium. Appl Immunohistochem Mol Morphol. 2007;15(2):170-4. 
17. Lai MT, Hua CH, Tsai MH, Wan L, Lin YJ, Chen CM, et al. Talin-1 overexpression defines high risk for aggressive oral squamous cell carcinoma and promotes cancer metastasis. J Pathol. 2011;224(3):367-76.

18. Sakamoto S, McCann RO, Dhir R, Kyprianou N. Talin1 promotes tumor invasion and metastasis via focal adhesion signaling and anoikis resistance. Cancer Res. 2010;70(5):1885-95.

19. Zhang JL, Qian YB, Zhu LX, Xiong QR. Talin1, a valuable marker for diagnosis and prognostic assessment of human hepatocelluar carcinomas. Asian Pac J Cancer Prev. 2011;12(12):3265-9.

20. Kanamori H, Kawakami T, Effendi K, Yamazaki K, Mori T, Ebinuma $H$, et al. Identification by differential tissue proteome analysis of talin-1 as a nove molecular marker of progression of hepatocellular carcinoma. Oncology. 2011;80(5-6):406-15.

21. Chen $Y$, Liu MZ, Liang SB, Zong JF, Mao YP, Tang LL, et al. Preliminary results of a prospective randomized trial comparing concurrent chemoradiotherapy plus adjuvant chemotherapy with radiotherapy alone in patients with locoregionally advanced nasopharyngeal carcinoma in endemic regions of china. Int J Radiat Oncol Biol Phys. 2008;71(5):1356-64.

22. Chan AT, Teo PM, Ngan RK, Leung TW, Lau WH, Zee B, et al. Concurrent chemotherapy-radiotherapy compared with radiotherapy alone in locoregionally advanced nasopharyngeal carcinoma: progression-free survival analysis of a phase III randomized trial. J Clin Oncol. 2002;20(8):2038-44.

23. Li W, Yu CP, Xia JT, Zhang L, Weng GX, Zheng HQ, et al. Sphingosine kinase 1 is associated with gastric cancer progression and poor survival of patients. Clin Cancer Res. 2009;15(4):1393-9.

24. Liao WT, Wang X, Xu LH, Kong QL, Yu CP, Li MZ, et al. Centromere protein $\mathrm{H}$ is a novel prognostic marker for human nonsmall cell lung cancer progression and overall patient survival. Cancer. 2009;115(7):1507-17.

25. Zlobec I, Steele R, Terracciano L, Jass JR, Lugli A. Selecting immunohistochemical cut-off scores for novel biomarkers of progression and survival in colorectal cancer. J Clin Pathol. 2007;60(10):1112-6.

26. Zweig MH, Campbell G. Receiver-operating characteristic (ROC) plots: a fundamental evaluation tool in clinical medicine. Clin Chem. 1993;39(4):561-77.

27. Reid JF, Lusa L, De Cecco L, Coradini D, Veneroni S, Daidone MG, et al. Limits of predictive models using microarray data for breast cancer clinical treatment outcome. J Natl Cancer Inst. 2005;97(12):927-30.

28. Snijders AM, Schmidt BL, Fridlyand J, Dekker N, Pinkel D, Jordan RC, et al. Rare amplicons implicate frequent deregulation of cell fate specification pathways in oral squamous cell carcinoma. Oncogene. 2005;24(26):4232-42.

29. Singel SM, Cornelius C, Batten K, Fasciani G, Wright WE, Lum L, et al. A targeted RNAi screen of the breast cancer genome identifies KIF14 and TLN1 as genes that modulate docetaxel chemosensitivity in triple-negative breast cancer. Clin Cancer Res. 2013;19(8):2061-70.

30. Lai SZ, Li WF, Chen L, Luo W, Chen YY, Liu LZ, et al. How does intensitymodulated radiotherapy versus conventional two-dimensional radiotherapy influence the treatment results in nasopharyngeal carcinoma patients? Int J Radiat Oncol Biol Phys. 2011;80(3):661-8.

31. Canel M, Secades P, Garzon-Arango M, Allonca E, Suarez C, Serrels A, et al. Involvement of focal adhesion kinase in cellular invasion of head and neck squamous cell carcinomas via regulation of MMP-2 expression. Br J Cancer. 2008;98(7):1274-84.

32. Hannigan GE, Leung-Hagesteijn C, Fitz-Gibbon L, Coppolino MG, Radeva G, Filmus J, et al. Regulation of cell adhesion and anchorage-dependent growth by a new beta 1-integrin-linked protein kinase. Nature. 1996:379(6560):91-6

33. Tanentzapf G, Martin-Bermudo MD, Hicks MS, Brown NH. Multiple factors contribute to integrin-talin interactions in vivo. J Cell Sci. 2006:119(Pt 8):1632-44.

34. Critchley DR. Cytoskeletal proteins talin and vinculin in integrin-mediated adhesion. Biochem Soc Trans. 2004;32(Pt 5):831-6.

35. Calderwood DA. Integrin activation. J Cell Sci. 2004;117(Pt 5):657-66.

36. Fong YC, Liu SC, Huang CY, Li TM, Hsu SF, Kao ST, et al. Osteopontin increases lung cancer cells migration via activation of the alphavbeta3 integrin/FAK/Akt and NF-kappaB-dependent pathway. Lung Cancer. 2009;64(3):263-70.

37. Osaki M, Oshimura M, Ito H. PI3K-Akt pathway: its functions and alterations in human cancer. Apoptosis. 2004;9(6):667-76.

38. Hwang YP, Yun HJ, Choi JH, Han EH, Kim HG, Song GY, et al. Suppression of EGF-induced tumor cell migration and matrix metalloproteinase-9 expression by capsaicin via the inhibition of EGFR-mediated FAK/Akt, PKC/Raf/ERK, p38 MAPK, and AP-1 signaling. Mol Nutr Food Res. 2011;55(4):594-605.
39. Ren $\mathrm{K}$, Jin H, Bian C, He H, Liu X, Zhang S, et al. MR-1 modulates proliferation and migration of human hepatoma HepG2 cells through myosin light chains-2 (MLC2)/focal adhesion kinase (FAK)/Akt signaling pathway. J Biol Chem. 2008;283(51):35598-605.

40. Wegener $\mathrm{KL}$, Partridge AW, Han J, Pickford AR, Liddington RC, Ginsberg MH, et al. Structural basis of integrin activation by talin. Cell. 2007;128(1):171-82.

41. Tang H, Yao L, Tao X, Yu Y, Chen M, Zhang R, et al. miR-9 functions as a tumor suppressor in ovarian serous carcinoma by targeting TLN1. Int J Mol Med. 2013;32(2):381-8.

\section{Submit your next manuscript to BioMed Central and take full advantage of:}

- Convenient online submission

- Thorough peer review

- No space constraints or color figure charges

- Immediate publication on acceptance

- Inclusion in PubMed, CAS, Scopus and Google Scholar

- Research which is freely available for redistribution

Submit your manuscript at www.biomedcentral.com/submit 